International Journal of Bioscience and Medicine
(ISSN:2575-7814)

\title{
SIGNS OF SUCETTABILITY ASSOCIATED WITH EXTRINSIC FACTORS TO FUNGAL INFECTION BY THE GENUS SPOROTHRIX SPP.
}

\section{Rubens Barbosa Rezende ${ }^{1 *}$, Larissa Teodoro}

${ }^{1}$ Faculdade Santa Rita (FASAR), Conselheiro Lafaiete - MG; ${ }^{2}$ Instituto de Ciências da Saúde da Universidade Paulista (UNIP), Campinas - SP.

\section{ABSTRACT}

Objective: To evaluate the susceptibility to infection by the genus sporothrix spp.; targeting patients with immunosuppression due to the use of inadequate medication, seropositive patients (carriers of Human Immunodeficiency Syndrome - HIV) and alcoholics dependents. Method: This is an integrative review of the literature available in the PUBMED database, using the descriptors: "Sporotrichosis", "Fungi" and "Sporothrix", duly registered in $\mathrm{MeSH}$, using the boolean operator AND. A total of 128 articles were found and evaluated and, at the end, 15 were selected to compose this review. The inclusion criteria were: full articles, available free of charge, published in English between 2010 and 2020. Results: Sporotrichosis is clinically characterized in fixed cutaneous, lymphocutaneous, disseminated cutaneous and extracutaneous. Frequently the appearance of disseminated cutaneous sporotrichosis occurs especially in immunosuppressed individuals. The four cases evaluated have as etiological agent in common, the genus Sporothrix spp., distinguishing the species, the contagion, clinical aspects and their susceptibility factors. Conclusion: However, most cases of sporotrichosis are related to a dysfunction of the immune system. As well, the unusual cases characterize a challenge to reliable diagnosis and can often lead to a wrong pharmacological therapy.

Keywords: Sporotrichosis, Fungi, Sporothrix.
*Correspondence to Author: Rubens Barbosa Rezende Faculdade Santa Rita (FASAR), Conselheiro Lafaiete - MG;

How to cite this article:

Rubens Barbosa Rezende, Larissa Teodoro.SIGNS OF SUCETTABILITY ASSOCIATED WITH EXTRINSIC FACTORS TO FUNGAL INFECTION BY THE GENUS SPOROTHRIX SPP.. International Journal of Bioscience and Medicine, 2021; 4:14.

\section{eScî̀Pub}

eSciPub LLC, Houston, TX USA. Website: https://escipub.com/ 


\section{INTRODUCTION}

The dimorphic fungus Sporothrix schenckii is one of the etiological agents of sporotrichosis, in which it is found mainly in tropical and subtropical areas, but has been described worldwide. Infection is often caused by traumatic inoculation of organic matter containing the fungus, such as soil and plants. The classification of the species Sporothrix schenckii is defined as an eukaryotic and heterotrophic being, not mobile, and with chitin in its cell wall. ${ }^{1}$

The frequency of lesions caused by sporotrichosis is limited to the skin, as well as to subcutaneous cell tissue and adjacent lymphatic vessels. This fungus probably has the capacity to spread to other organs and, being an alternative, in unusual conditions, the aspiration of conidia, which can trigger a systemic level disease. In vitro culture is given as the gold standard for characterization of the etiological agent. However, other means are used to aid diagnosis, such as molecular, histopathological and serological tests. ${ }^{1}$

It is known that many factors act on the different clinical aspects of the disease, such as the status of the host's immune system and the virulence of the inoculated strain. Thus, the objective was to evaluate the susceptibility to infection by the genus sporothrix spp.; targeting patients with immunosuppression due to the use of inadequate medication, seropositive patients (carriers of Human Immunodeficiency Syndrome - HIV) and alcoholics dependentes.

\section{METHODS}

This is an integrative review of the literature available in the PUBMED database, using the descriptors: "Sporotrichosis", "Fungi" and "Sporothrix", duly registered in MeSH, using the boolean operator AND. A total of 128 articles were found and evaluated and, at the end, 15 were selected to compose this review. The inclusion criteria were: complete articles, available free of charge, published in English between the years 2010 to 2020. And as exclusion criteria were: articles in other languages, not available for free and in which sporotrichosis was not associated with predisposing factors.

\section{RESULTS}

Among neglected fungal infections is sporotrichosis, in which it is usually related to the species Sporothrix schenckii, a dimorphic microorganism that it first reported over a century ago, in rodent specimens (rats) and in man. However, the epidemiology, followed by the clinical picture and the essential aspects of sporotrichosis suffer great modifications, becoming considered a zoonotic disease, not only caused by a fungal species, and is related to high rates of morbidity and, in the filthy depressed host the death caused by this infection is common. ${ }^{2}$

Until then, the species $S$. brasiliensis was identified only in Brazil, whereas S. globosa has predominance in Asia; and S. schenckii, has worldwide distribution, since it has many reported cases. $^{2}$ Gender infection is not a reported disease, and therefore its exact prevalence is obscure, cases have been described in Australia, the United States, and some countries in South America and Asia. After some outbreaks in France in the last century, the rate of cases has been minimized and sporotrichosis is rarely identified on the European continente. ${ }^{3}$

Sporothrix infection is characterized as the most frequent subcutaneous mycosis, and is usually contracted by traumatic inoculation of the fungus. In microscopic visualization, the presence of the fungus in animal and human tissues, in the form of sprouting yeasts, is notorious, being observed in different shapes and sizes. They are characterized by their oval to rounded morphology, having a diameter between 2 to $6 \mu \mathrm{m}$, and usually have elongated buds that resemble cigars in a narrow base. Macroscopically, yeast colonies are characterized by smooth textures, and brown or cream color. ${ }^{1}$ 
Some species of the genus Sporothrix were identified by molecular techniques, and among these species are $S$. albicans, S. mexicana, $S$. globosa, S. brasiliensis and S. schenckii sensu stricto. ${ }^{4}$ The genus undergoes a change in its morphology in response to temperature, progressing as yeast in the host tissue at $37^{\circ} \mathrm{C}$ or as filamentous hyphae throughout its saprophytic stage at $25^{\circ} \mathrm{C} .^{5}$ Sporotrichosis is clinically characterized in fixed, lymphocutaneous (most common), extracutaneous, and disseminated cutaneous (less common) and generally associated with immunosuppressed individuals. ${ }^{6}$

\section{DISCUSSION}

Among endemic mycoses, sporotrichosis is specific in the high prevalence of animal-human disease transmissibility. However, it has not yet been elucidated how the yeast phase disseminates the infection by this route, and it is generally accepted that the mycelial phase contains the infectious propagules for humans. However, according to the literature, many studies show that feline transmissibility offers a clear basis for this medium of infection. ${ }^{3}$

The immune system responses involved in prophylaxis and sporotrichosis containment are not yet well elucidated. The literature reports that cellular immunity plays an essential role in the success of infection, with the primary response having the control of the situation, but more recent data sustain that the humoral response is fundamental for the adequate infection control. ${ }^{7}$

In the research of Gandhi and collaborators (2016), the case of a 54 year old healthy male patient with ulcers of various sizes and that did not heal, of location on the right leg for a period of three months, is addressed. The patient was given many cycles of intravenous and oral antibiotics, and the ulcers were still evolving. No apparent history of trauma or evidence of an immunodeprived system. The patient reported during the anamnesis a trip to the Amazon forest one month before the ulcers appeared. With the diagnosis, classical lymphocutaneous sporotrichosis was identified, with nodulo- ulcerative lesions with linear distribution, throughout the lymphatic tract. It is noted that the multiple progressive ulcers diagnosed in the patient are distinguished from the typical sporotrichosis, since it had an inflamed and cellulite background. The literature reports that atypical forms of the disease have been found in several countries, being mostly in patients with a depressed immune system, or in those where the drug administration was erroneously done with immunosuppressants. Gandhi and collaborators (2016) stressed that the atypical emergence of the disease in individuals with immunosuppression is unusual. Another hypothesis raised, would be species with high virulence load, such as S. brasiliensis, characterized by atypical disseminated skin infections, in which the species is hyperendemic in Brazil, corroborating that the patient traveled to the forest, therefore, was associated with the species in question, as the etiological agent. With everything, it was not possible the exact diagnosis of the species, because there was no growth in the culture and did not carry more inputs and resources to perform other tests. ${ }^{8}$

Patel and collaborators (2016) in their work, were highlighted the case of a 27 year old woman, HIV positive, with severe immunosuppression. She was diagnosed with disseminated skin sporotrichosis with the presence of atypical skin lesions. ${ }^{9}$ The literature reports that patients with HIV are more likely to progress with deep fungal infections disseminated at a lethal level. However, data on HIV co-infection and the fungal infection in question are scarce. And it is noted that when it happens, it is acutely disseminated, with a lower CD4 count compared to normal. ${ }^{10}$ During the anamnesis, the patient reports being a gardener, suggesting that her form of infection was by accidental inoculation during her work. ${ }^{9}$

Barros and collaborators (2020) in her research, was reported the case of a man, 44 years old, diagnosed with subcutaneous nodules in which they caused an inflammatory storm after the drainage of secretion and seropurulent 
ulceration. During the anamnesis, the patient reported being an ethylist for more than five years and had contact with cats. Based on the epidemiological history added to the elocution of the lesions, the hypothesis was fungal infection by the genus Sporothrix. The culture of liquid aspirate from the nodules was carried out, five days after sowing, it had growth to the genus Sporothrix. The battery of laboratory tests was within normal limits, and the serological tests for HIV, HTLV, VDRL, and hepatitis B and C were non-reactive (negative). ${ }^{11} \quad$ Systemic sporotrichosis was diagnosed, and this classification was based on Orofino-Costa and collaborators (2017), in which it was described the abundant appearance of an individual with a depressed immune system with alcoholism. ${ }^{12}$ Since the excessive and chronic ingestion of alcoholic beverages leads to lymphopenia and consequent chronic activation of the T cell pool, in which they are able to alter the ability of these cells to expand and respond to pathogens, which causes a state of anergy and altering the response Th1 and Th2, ${ }^{13}$ being the Th1, the main source of combating a fungal infection. ${ }^{11}$

For Benvegnú and collaborators (2017), the case of a man, 47 years old, having as profession, farmer, was reported. He was identified on his left leg, a lump, detached and painless one year ago. The rapid evolution of the disseminated skin lesions was followed, in this period the purulent secretion was drained and there was a loss of weight, 13 kilograms in the last three months. The man had no medical condition, only alcoholism for more than three decades, therefore, based on the data, it was diagnosed sporotrichosis of the skin disseminated non-systemic, in an ethylist man who during his anamnesis reported to reside in an endemic site of the disease. ${ }^{14}$ The hypothesis of susceptibility to fungal infection was alcoholic dependence, which corroborates with the case described by Barros and collaborators (2020), however, distinguishing in the diagnosis, such cases were compared to emphasize that even having the extrinsic factor, alcoholic dependence, they had singular diseases. ${ }^{11}$

The literature emphasize that the immunological response to the fungal infection by the genus Sporothrix is based on in vitro studies and experimental specimen of rodents, being the data from humans still scarce. ${ }^{15}$

\section{CONCLUSION}

However, most cases of sporotrichosis are related to a dysfunction of the immune system. As well, unusual cases present a challenge to reliable diagnosis and can often lead to erroneous pharmacological therapy. Therefore, further research directed at the fungus-host mechanism is essential, since there is little information regarding the response of the immune system to infection by the etiologic agent.

\section{REFERENCES}

[1]. BARROS, M. B. L.; PAES, R. A.; SCHUBACH, A. O. Sporothrix schenckii and Sporotrichosis. Clinical Microbiology Reviews Oct 2011, 24 (4) 633-654.

[2]. MORA-MONTES HM. Special Issue "Sporothrix and Sporotrichosis". J Fungi (Basel). 2018 Oct 12;4(4):116. doi: 10.3390/jof4040116. PMID: 30321990; PMCID: PMC6308924.

[3]. CHAKRABARTI A, BONIFAZ A, GUTIERREZGALHARDO MC, MOCHIZUKI T, LI S. Global epidemiology of sporotrichosis. Med Mycol. 2015 Jan;53(1):3-14. doi: 10.1093/mmy/myu062. Epub 2014 Dec 19. PMID: 25526781.

[4]. VÁSQUEZ-DEL-MERCADO E, ARENAS R, PADILLA-DESGARENES C. Sporotrichosis. Clin Dermatol. 2012 Jul-Aug;30(4):437-43. doi: 10.1016/j.clindermatol.2011.09.017. PMID: 22682194.

[5]. RODRIGUES AM, DE HOOG GS, DE CAMARGO ZP. Sporothrix Species Causing Outbreaks in Animals and Humans Driven by Animal-Animal Transmission. PLoS Pathog. 2016. $12 \quad$ (7): $\quad$ e1005638. https://doi.org/10.1371/journal.ppat.1005638.

[6]. YAP FB. Disseminated cutaneous sporotrichosis in an immunocompetent individual. Int J Infect Dis. 2011;15(10):e727e729.

[7]. GARCÍA CARNERO LC, LOZOYA PÉREZ NE, GONZÁLEZ HERNÁNDEZ SE, MARTÍNEZ ÁLVAREZ JA. Immunity and Treatment of 
Sporotrichosis. J Fungi (Basel). 2018 Aug

20;4(3):100. doi: 10.3390/jof4030100. PMID: 30127270; PMCID: PMC6162376.

[8]. GANDHI N, CHANDER R, JAIN A, SANKE S, GARG T. Atypical cutaneous sporotrichosis in an immunocompetent adult: Response to potassium iodide. Indian $J$ Dermatol 2016;61:236.

[9]. PATEL A., MUDENDA V., LAKHI S., NGALAMIKA O. A 27-Year-Old Severely Immunosuppressed Female with Misleading Clinical Features of Disseminated Cutaneous Sporotrichosis. Case Rep Dermatol Med. 2016;2016:9403690.

[10]. MOREIRA, J. A. S.; FREITAS, D. F. S.; LAMAS, C. C. "The impact of sporotrichosis in HIVinfected patients: a systematic review," Infection, vol. 43, no. 3, pp. 267-276, 2015.

[11]. BARROS NM, PESSOA AS, BROTAS AM. Systemic sporotrichosis in an alcoholic patient. An Bras Dermatol. 2020;95(3):376-378.

[12]. OROFINO-COSTA, R.; MACEDO, P. M.; RODRIGUES, A. M.; BERNARDESENGEMANN, A. R. Sporotrichosis: an update on epidemiology, etiopathogenesis, laboratory and clinical therapeutics. An Bras Dermatol., 92 (2017), pp. 606-620.

[13]. PASALA, S.; BARR, T.; MESSAOUDI, I. Impact of Alcohol Abuse on the Adaptive Immune System. Alcohol Res., 37 (2015), pp. 185-197.

[14]. BENVEGNÚ, A. M.; STRAMARI, J.; DALLAZEM, L. N. D.; CHEMELLO, R. M. L.; BEBER, A. A. C. Disseminated cutaneous sporotrichosis in patient with alcoholism. Rev. Soc. Bras. Med. Trop. 2017, 50 (6), 871-873.

[15]. QUEIROZ-TELLES, F., BUCCHERI, R., \& BENARD, G. Sporotrichosis In Immunocompromised Hosts. Journal of Fungi, 2019, 5(1), 8. 